International Journal of Engineering \& Technology, 7 (4.7) (2018) 212-214
International Journal of Engineering \& Technology
SPC
Website: www.sciencepubco.com/index.php/IJET
Research paper

\title{
Laboratory Research of the Effect Fertilizers on the Soil Structure
}

\author{
Rodion V. Okunev, Elena S. Vaganova \\ Kazan Federal University \\ *Corresponding author E-mail: tutinkaz@yandex.ru
}

\begin{abstract}
Phosphorus is an important element of plant nutrition, affecting the biotransformation of nitrogen in soils. The effect of the application of phosphorus fertilizers on the mineralization of nitrogen in soils is actively studied, however, little attention is paid to their effect on the content of intermediate mineralization compounds, such as free amino acids. This study evaluated the effect of various doses of ground phosphate flour and simple superphosphate $(0 ; 1.0,2.1,4.2,10.6,53.1,212.5,1062.5 \mathrm{~g} \mathrm{~kg}-1)$ in the incubation experiment on the content of 15 free amino acids in the soil. At various doses of ground phosphate flour, the total content of free amino acids ranged from $7.8 \pm 1.1$ to $14.4 \pm 2.1 \mu \mathrm{g} \mathrm{kg}^{-1}$, even the minimum recommended dose of ground phosphate flour $\left(1.0 \mathrm{~g} \mathrm{~kg}^{-1}\right)$ caused a significant decrease in their concentration. A high correlation between the amino acid concentration and the microbial biomass of the soil $\left(\mathrm{C}_{\text {mic }}\right)$ is shown. In general, the use of superphosphate positively influenced both the microbial biomass of the soil and the content of free amino acids. At various fertilizer doses, the total concentration of free amino acids significantly increased in comparison with the control and varied from $37.5 \pm 8.5$ to $67.1 \pm 15.2 \mu \mathrm{g} \mathrm{kg}^{-1}$.
\end{abstract}

Keywords: free amino acids, incubation experience, ground phosphate flour, phosphoric fertilizers, superphosphate.

\section{Introduction}

The problem of phosphorus deficiency in soil is acute, affecting almost a third of terrestrial soils in the world $[1,2]$. The fight against phosphorus deficiency is quite successful by using phosphorus fertilizers of various types. Some well-soluble salts of phosphoric acids, widely used in agriculture as highly effective fertilizers, because of their high mobility, are washed into water bodies and cause eutrophication of river and lake water, while phosphorus of solid phosphorus fertilizers inefficiently and slowly saturates the soil with a nutrient necessary for plants. Recently, the possibility of using nanosized synthetic phosphoric fertilizers that are able to supply a sufficient amount of nutrients to plants, but will have less mobility, is being investigated [3]. All these fertilizers in one way or another saturate the soil with necessary for plant nutrition element. Simultaneously with plants, a nutrient substrate is also obtained from soil microorganisms. The use of phosphorus fertilizers can lead to the activation of the activity of phosphatedissolving microorganisms and the enrichment of the bacterial community [4], which in turn can accelerate the decomposition of organic soil and promote the release of nitrogen. Therefore, phosphorus is an important element of plant nutrition, which affects nitrogen biotransformation in soils. Its influence on the mineralization of nitrogen-containing compounds is actively studied [2,5]. However, there is practically no information on the effect of phosphorus fertilizers on intermediate mineralization compounds, such as free amino acids (FA), which are released during mineralization of organic nitrogen-containing soil compounds [6].

\section{Methods}

Phosphate fertilizers were introduced into air-dry gray forest soil (the main soil characteristics are shown in Table 1) at doses of 0 ; $1.0 ; 2.1,4.2 ; 10.6 ; 53.1 ; 212.5,1062.5 \mathrm{~g} \mathrm{~kg}^{-1}$. These doses are selected based on recommendations for the use of fertilizer manufacturer. The used ground phosphate flour is a product of the processing of natural phosphorus-containing raw materials at the Yegoryevsky deposit (Kostroma Chemical Plant, Russia) with a $\mathrm{P}_{2} \mathrm{O}_{5}$ content of $19 \%$. The purchased superphosphate contains at least $26 \%$ of $\mathrm{P}_{2} \mathrm{O}_{5}$ (Rusagrokhim, Russia). Further, the soil was incubated with the humidity ( $60 \%$ of the total moisture capacity of the soil), which is optimal for the life of microorganisms. After incubation, the free amino acids were removed with water. For this purpose, the soil was mixed in a shaker at $200 \mathrm{rpm}$ for 1 hour. The slurry suspension was then centrifuged at 4,000 rpm, the supernatant was filtered through membrane filters with a pore diameter of $0.2 \mu \mathrm{m}$ (Chromafil Xtra PA-20/25, Germany).

Table 1: Basic characteristics of soil (mean \pm standard deviation; $\mathrm{n}=3 ; P$ $<0.05)$

\begin{tabular}{|c|c|c|c|c|c|c|}
\hline $\begin{array}{c}\text { Soil } \\
\text { type }\end{array}$ & $\mathrm{C}_{\mathrm{org}}, \%$ & $\mathrm{pH}$ & Sand, \% & Silt, \% & Clay, \% & $\begin{array}{c}\mathrm{CEC} \\
\mathrm{mM} \mathrm{kg}\end{array}$ \\
\hline $\begin{array}{c}\text { Haplic } \\
\text { Luvi- } \\
\text { sol }\end{array}$ & $\begin{array}{c}3.2 \pm 0 . \\
1\end{array}$ & $\begin{array}{c}6.5 \pm 0 . \\
1\end{array}$ & $\begin{array}{c}55.0 \pm 0 . \\
1\end{array}$ & $\begin{array}{c}26.6 \pm 0 . \\
1\end{array}$ & $\begin{array}{c}18.4 \pm 0 . \\
1\end{array}$ & $247 \pm 6$ \\
\hline
\end{tabular}

${ }^{\text {a }}$ Cation exchange capacity.

The free amino acids extracted from soils were determined by HPLC with pre-columnar derivatization of amino acids by phenyl 
isothiocyanate [7]. The $400 \mu \mathrm{l}$ filtrates obtained after extraction of amino acids from the soil were dried at $65^{\circ} \mathrm{C}$ under vacuum. The dry residue was dissolved in $150 \mu \mathrm{l}$ methanol-water-triethylamine $(2: 2: 1)(\mathrm{v} / \mathrm{v})$, and the solution was evaporated in vacuum. Derivatization was carried out by the addition of $100 \mu 1$ methanol-watertriethylamine-phenyl isothiocyanate reagent in volume ratios of 7.5:1:1:1 (v/v). The tubes were vigorously shaken and left at room temperature for $20 \mathrm{~min}$. Then, to remove excess derivatizing reagent, the mixture was kept under vacuum at $50^{\circ} \mathrm{C}$. Before entering into HPLC, the dry residue was dissolved in $300 \mu \mathrm{l} 5 \mathrm{mmol}$ $\mathrm{Na}_{2} \mathrm{HPO}_{4}, \mathrm{pH} 7.4$ and passed through a membrane filter with a pore diameter of $0.2 \mu \mathrm{m}$.

The determination of free amino acids was carried out on Flexar high performance liquid chromatograph (Perkin Elmer, USA). Brownlee Analytical C18 (Perkin Elmer, USA) chromatographic column was used measuring $150 \times 4.6 \mathrm{~mm}$ packed with $3 \mu \mathrm{m}$ particles. The column was eluted at room temperature in a linear gradient using a system consisting of an aqueous buffer prepared by adding $0.5 \mu \mathrm{l}^{-1}$ triethylamine to a $0.14 \mathrm{M}$ solution of sodium acetate adjusted with acetic acid to $\mathrm{pH} 6.0$ (Eluent $\mathrm{A}$ ) and acetonitrile-water in a volume ratio of 60:40 (Eluent B). The flow rate of the mobile phase is $0.9 \mathrm{ml} \mathrm{min}^{-1}$. Identification of amino acid derivatives was carried out using a UV detector at a wavelength of $254 \mathrm{~nm}$ [8]. The calibration of the chromatograph was conducted using a mixture of standard samples of L-amino acids ("Sigma Aldrich", Belgium): alanine, arginine, asparagine, aspartic acid, valine, proline, histidine, glutamine, glutamic acid, isoleucine, leucine, lysine, serine, tyrosine, threonine, phenylalanine.

Microbial soil biomass was determined by recalculating the rate of substrate-induced respiration (SIR) [9]. SIR was determined by gas chromatography using Clarus-580 chromatograph, USA [10]. Statistical processing of the results was performed with Statistica 9.1 (StatSoft, Tulsa, USA). The data in the text and in the diagrams are presented as the mean \pm standard deviation $(n=3$; $\mathrm{p}<0.05$ ). To establish the relationship between the values of the variables, the Spearman correlation analysis was used. The significance of the differences between the variants was determined using ANOVA test for $\mathrm{p}<0.05$.

\section{Results and Discussion}

Long-term soil aging in the settings close to optimal for microorganisms, inevitably entails changes in the activity of soil microflo$\mathrm{ra}$, and, as a consequence, of the processes of transformation of organic nitrogen. As a result, changes affect the pool of free amino acids. So, before the incubation experiment was carried out, 15 free amino acids were found in the gray forest soil, the contents of which varied from 0.28 to $6.12 \mu \mathrm{g} \mathrm{kg}^{-1}$. Dominant polar amino acids were serine and glycine, which content was 6.12 and $3.9 \mu \mathrm{g}$ $\mathrm{kg}^{-1}$ (24.8\% and $16.0 \%$ of the total content of FA, respectively). Concentrations of negatively charged amino acids - aspartic and glutamic acid - were 1.56 and $0.98 \mu \mathrm{g} \mathrm{kg}^{-1}$, respectively. The number of positively charged amino acids (lysine, histidine, arginine) ranged from 0.74 to $1.59 \mu \mathrm{g} \mathrm{kg}^{-1}$. The content of the remaining amino acids (threonine, alanine, proline, tyrosine, valine, isoleucine, leucine, phenylalanine) was 0.28 to $3.94 \mu \mathrm{g} \mathrm{kg}^{-1}$. The total FA concentration was $24.67 \mu \mathrm{g} \mathrm{kg}^{-1}$, which does not contradict the data of the literature sources [11].

Changes in the content of free amino acids in gray forest soil enriched with various doses of ground phosphate flour were evaluated after 30 days of incubation. The control variant of the experiment (without the addition of ground phosphate flour), the total FA content was $17.3 \mu \mathrm{g} \mathrm{kg}^{-1}$ (Figure 1a). The dominant amino acids were Gly (29.2\% of the total FA content), Ser $(24.0 \%)$ and Val $(23.2 \%)$. Much lower content was found for tyrosine, threonine, alanine, histidine, leucine and isoleucine (1.2 to 4.9\%). Adding ground phosphate flour at the minimum dose level recommended for application to the soil $(1.0 \mathrm{~g} / \mathrm{kg})$ reduced the total amino acid content from $17.33 \pm 2.53 \mu \mathrm{g} \mathrm{kg}$ to $14.44 \pm 2.11 \mu \mathrm{g} \mathrm{kg}^{-1}$.
Further increase in fertilizer doses within the recommended limits (up to $4.2 \mathrm{~g} / \mathrm{kg}$ ) resulted in a decrease to $7.81 \pm 1.15 \mu \mathrm{g} \mathrm{kg}-1$.

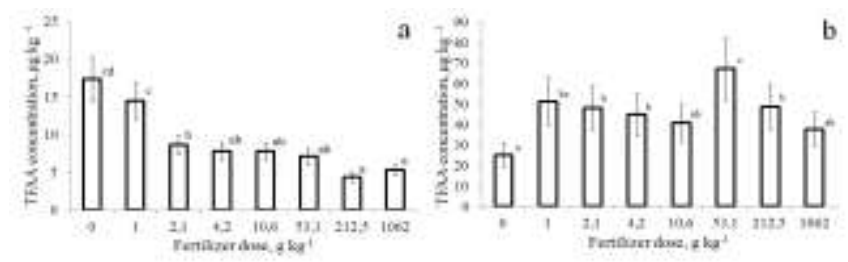

Figure 1:. Effect of phosphorite powder (a) and superphosphate (b) on total free amino acids (TFAA) content in soil (Values with different letters are significantly different at $\mathrm{P}<0.05$ )

The tendency to decrease was noted in practically all detected FA (except for isoleucine and leucine). Starting from $2.1 \mathrm{~g} \mathrm{~kg}^{-1}$, the alanine and histidine levels were below the detection limit (Figure 2). At fertilizer doses from 2.1 to $53.1 \mathrm{~g} \mathrm{~kg}^{-1}$, the total FA concentration did not change significantly, however, beginning with a dose of $53.1 \mathrm{~g} \mathrm{~kg}^{-1}$, threonine was no longer detected in the soil. At the highest possible doses of ground phosphate flour, the concentrations of FA reach their minimum. As a percentage of the increase in fertilizer doses, the relative content of glycine significantly decreases, but the content of tyrosine and valine increases.

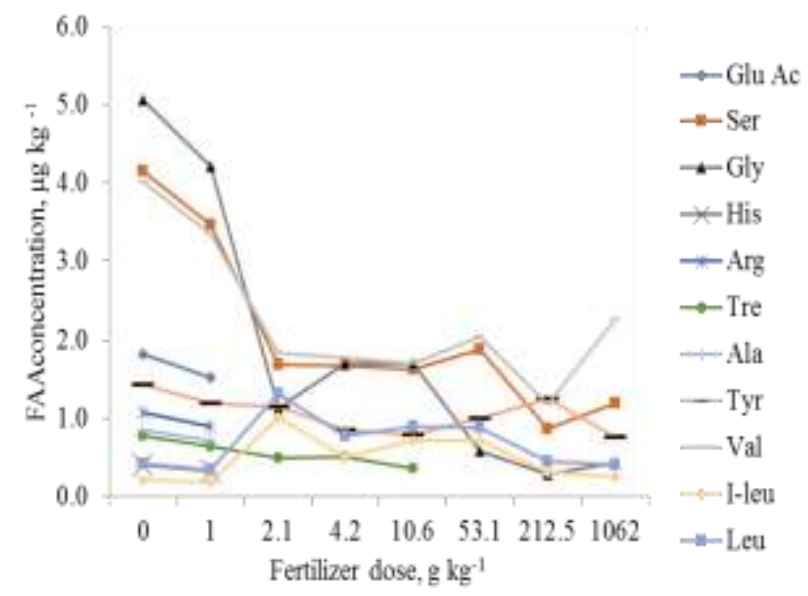

Figure 2:. Effect of phosphorite powder on selected free amino acids content in soil

The main effect on the formation of free amino acids is the vital activity of microorganisms. Approximately $40 \%$ of gross nitrogen is represented by peptides and proteins [6], and the bulk of free amino acids is the result of depolymerization of these proteins by extracellular enzymes [12]. The microbial soil biomass determined by recalculating the SIR speed for the control soil was $2.5 \pm 0.5 \mathrm{~g} \mathrm{C}$ $\mathrm{kg}^{-1}$ soil (Figure 3a). Further, with an increase in the fertilizer dose the index gradually decreased, reaching a minimum of $1.9 \pm 0.3 \mathrm{~g} \mathrm{C}$ $\mathrm{kg}^{-1}$ of soil at the maximum content of ground phosphate flour. Such a negative effect of phosphorus fertilizers on the soil microflora is found in the case of its significant effect on the acidity of the soil [13]. A high correlation $(\mathrm{r}=0.95)$ between the total content of free amino acids and $S_{\text {micr }}$ shows that with decreasing microbial biomass, a decrease in the content of free amino acids is observed.
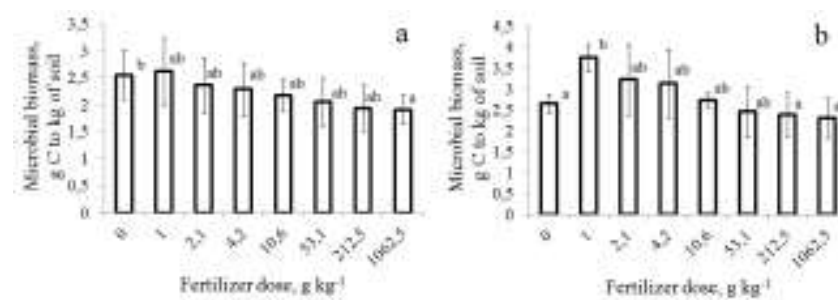

Figure 3:. Effect of phosphorite powder (a) and superphosphate (b) on soil microbial biomass (Values with different letters are significantly different at $\mathrm{P}<0.05$ ) 
Introduction of superphosphate somewhat differently affected the content of free amino acids. The main difference from the effect of applying phosphate flour can be considered an increase in the total content of FA (Figure 1b). The minimum dose of superphosphate $\left(1 \mathrm{~g} \mathrm{~kg}^{-1}\right)$ increased the concentration of amino acids to $51.2 \pm 11.6$ $\mu \mathrm{g} \mathrm{kg}^{-1}$. Further increase in fertilizer doses in the range of 2.1-10.6 $\mathrm{g} \mathrm{kg}^{-1}$ led to a slight decrease in their content compared to the first maximum. A second maximum of FA concentration was observed at a dose of $53.1 \mathrm{~g} \mathrm{~kg}^{-1}$ of fertilizer. An increase in the content compared to the control soil was observed for almost all amino acids (Figure 4), but the percentage ratio varied slightly. High doses of fertilizer led to a relative decrease in the content of glycine and serine, but slightly increased the concentration of arginine and threonine.

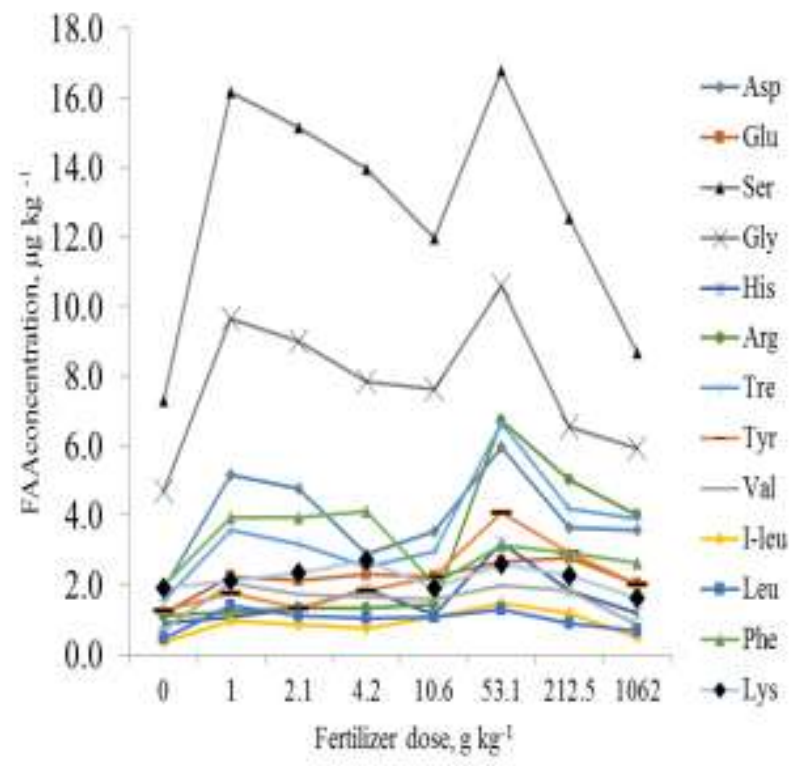

Figure 4:. Effect of superphosphate on selected free amino acids content in soil

The index of microbial biomass when applying various doses of superphosphate to the soil is generally somewhat higher than during introduction of ground phosphate flour (Figure $3 \mathrm{~b}$ ). This can be explained by the fact that superphosphate is much more soluble in soils, and during the incubation microorganisms received more nutrient than with phosphate flour. In addition, in the production of superphosphate, fertilizer is treated with ammonium, therefore, together with phosphorus, 6-9\% of mineral nitrogen enters the soil, which is also one of the main nutrient elements of microorganisms. Application of nitrogen or carbon sources together with phosphorus favorably influences soil microflora. However, increasing the doses of superphosphate somewhat reduces the biomass of microbes, which is likely, as in the case of phosphate flour, due to a change in the acidity of the medium affecting the activity of microorganisms. The correlation between the total content of free amino acids and $\mathrm{C}_{\text {mic }}$ was $\mathrm{r}=0.90$.

\section{Summary}

Thus, at various doses of ground phosphate flour, the total content of free amino acids ranged from $7.8 \pm 1.1$ to $14.4 \pm 2.1 \mu \mathrm{g} \mathrm{kg}^{-1}$, even the minimum recommended dose of ground phosphate flour $(1.0 \mathrm{~g}$ $\mathrm{kg}^{-1}$ ) caused a significant decrease in their concentration. The amount of amino acids identified after introducing high doses of ground phosphate flour decreased from 9 to 6 . Introduction of different doses of superphosphate, on the contrary, led to a significant increase in the total concentration of free amino acids in comparison with the control and varied from $37.5 \pm 8.5$ to $67.1 \pm 15.2 \mu \mathrm{g} \mathrm{kg}^{-1}$; an increase in the fertilizer dose showed a slight decrease compared to the maximum at low doses. Correla- tion analysis showed a high correlation between the microbial biomass index of the soil and the content of free amino acids, both in the case of ground phosphate flour $(r=0.95)$ and superphosphate $(\mathrm{r}=0.90)$.

\section{Conclusions}

A 30-day incubation laboratory experiment showed that phosphorus fertilizers can make changes to the pool of free amino acids in the soil. The use of even small doses of phosphate flour can significantly reduce their concentration. The microorganisms of the soil, which biomass has changed under the influence of fertilizer application, can have a great influence on the change in the content of FA. Thus, the conducted experiment showed a high correlation between the concentration of amino acids and the index of microbial biomass of the soil. The use of superphosphate, in contrast to ground phosphate flour, in general, positively affected both the microbial biomass of the soil and the content of free amino acids.

\section{Acknowledgements}

The work is performed according to the Russian Government Program of Competitive Growth of Kazan Federal University.

\section{References}

[1] L. Li, S.M. Li, J.H.Sun, L.L. Zhou, X.G. Bao, H.G. Zhang, F.S Zhang, Diversity enhances agricultural productivity via rhizosphere phosphorus facilitation on phosphorus-deficient soils, Proc. Natl. Acad. Sci. U. S. A., vol. 27, pp. 11192-11196, 2007.

[2] Y. Chen, T.-T. Sun, H.-Y. Qian, J.-B. Fan, Y.-Q. He, B. Sun, Nitrogen mineralization as a result of phosphorus supplementation in long-term phosphate deficient soil, Applied Soil Ecology, vol. 106, pp. 24-32, 2016

[3] R Liu, R. Lal, Synthetic apatite nanoparticles as a phosphorus fertilizer for soybean (Glycine max), Sci Rep., vol. 4. 5686, 2014.

[4] Y. Chen, J.B. Fan, L. Du, H.Xu, Q.H. Zhang, Y.Q. He, The application of phosphate solubilizing endophyte Pantoea dispersa triggers the microbial community in red acidic soil, Appl. Soil Ecol., vol. 84, pp. 235-244, 2014

[5] A.K. Kurishbaev, R.Kh. Ramazanova, G.R. Kekilbaeva, A. Kasipkhan. Effect of fertilizers on the content of humus and nitrate nitrogen in dark chestnut soil under spring triticale crops in Northern Kazakhstan. Bulletin of the Altai State Agrarian University, No. 1, p. 47-50, 2018

[6] H.R. Schulten, M. Schnitzer, The chemistry of soil organic nitrogen: a review. Biol. Fertil. Soils, vol. 26, pp.1-15, 1997.

[7] R.V. Okunev, L.M. Sungatullina, B.R. Grigoryan, Influence of sodium arsenate $(\mathrm{V})$ on the content of nitrogen-containing compounds in soil. Int. J. Appl. Eng Res., vol.10, pp. 44934-44938, 2015.

[8] R.V. Okunev, B.R. Grigorian. The influence of arsenic on the content of free amino acids of the soil. Bulletin of Kazan University. Series: Natural Sciences, Vol.157, No.2, p. 75-80, 2015.

[9] N.D. Ananieva, E.V. Blagodatskaia, D.G. Orlinskii. Methodical aspects of determining the rate of substrate-induced respiration of soil microorganisms. Soil Science, No.11, p. 72-77, 1993.

[10] E.V. Smirnova, K.G. Giniyatullin, R.V. Okunev, A.A. Valeeva, I.A Guseva, The Effect of Pre-Incubation Duration of Soil-Biochar Model Mixtures On the Results of Determination the Intensity of Substrate-Induced Respiration (Methodological Aspects of Study), Research Journal of Pharmaceutical, Biological and Chemical Sciences, vol. 7(5), pp.1360-1366, 2016

[11] D.L. Jones, S.J. Kemmitt, D. Wright, S.P. Cuttle, R. Bol, A.C. Edwards, Rapid intrinsic rates of amino acid biodegradation in soils are unaffected by agricultural management strategy, Soil Biol. Biochem., vol. 37, pp. 1267-1275, 2005.

[12] X Cao, Q. Ma, L. Wu, L. Zhu, Q. Jin, Effects of ammonium application rate on uptake of soil adsorbed amino acids by rice, $J$. Zhejiang Univ-Sci. B, vol. 17, pp. 294-302, 2016.

[13] C. Giovannini, J.M. Garcia-Mina, C. Ciavatta, C. Marzadori, Effect of organic-complexed superphosphates on microbial biomass and microbial activity of soil, Biology and Fertility of Soils, vol. 49, №4, pp 395-401, 2013. 